\title{
Risk Factors for Child Sexual Abuse and Perpetrator Related Risk Factors at Adama Hospital Medical College, Adama, Ethiopia
}

\author{
Nuru Hassen Ibrahim \\ School of Social and Public Health Department, Adama Hospital Medical College, Adama, Ethiopia
}

Email address:

nurulove27@gmail.com

To cite this article:

Nuru Hassen Ibrahim. Risk Factors for Child Sexual Abuse and Perpetrator Related Risk Factors at Adama Hospital Medical College, Adama, Ethiopia. Advances in Sciences and Humanities. Vol. 3, No. 3, 2017, pp. 23-30. doi: 10.11648/j.ash.20170303.12

Received: May 12, 2017; Accepted: June 15, 2017; Published: July 27, 2017

\begin{abstract}
Information regarding risk factors for child sexual abuse and perpetrators related risk factors were scarce in Ethiopia, even not considered as taboos till few decades and now has become one of the most high-profile crimes. The aim of this study is to identify and assess risk factors for child sexual abuse and perpetrators related risk factors in child sexual abuse. To conduct the study, quantitative method was employed and a survey was conducted from October 2016 to April 2017. A sample of 300 sexually abused children was selected for the study. A Questionnaire was developed according to the objective of the study and translated into the local language (Amharic language). To ensure the validity and reliability of developed questionnaire various measures were taken and a pilot study was conducted at the study site. The data were analyzed using frequency, percentage, through Statistical Package for the Social Sciences version 20.0 statistical packages. The results showed that $98 \%$ of sexually abused children's are female, in which $76.7 \%$ of them are $\mathrm{b} / \mathrm{n}$ age $13-18 \mathrm{yrs}$. The mean age of sexually abused children is 14 years and the minimum age is 2 years old. $87.7 \%$ sexually abused children do not know their perpetrators, and $10.3 \%$ sexually abused in group cohesion. All perpetrators are male sex, age regimen 18-35 years high score for which $8 \%$ of them had recognized physical or mental disability. Cousin score $47.6 \%$ of the total number of perpetrators who sexually abuses children by family members. $18.6 \%$ and $25 \%$ of perpetrators consume alcohol and multi drug in their daily life respectively in which $0.3 \%$ of them had identified repeated child sexual abuse in their past life. Based on the study finding factors for child and perpetrators risk factors in child sexual abuse in the study area needs collaborative hierarchal response.
\end{abstract}

Keywords: Child, Child Sexual Abuse, Risk Factors, Perpetrator

\section{Introduction}

"Child sexual abuse is any interaction between a child and an adult or older child in which the child is used for the sexual stimulation of the perpetrator or an observer. Sexual abuse often involves direct physical contact, touching, kissing, fondling, rubbing, oral sex, or penetration of the vagina or anus [1]." Sometimes the sex offender may receive gratification just by exposing himself to a child, or by observing or filming a child removing his or her clothes [1]. "Offenders often may not use physical force, but may use play, deception, threats, or other coercive methods to engage youngsters and maintain their silence. Child sexual abuse is a problem that breeds in secrecy. Speaking openly and publicly about it will enhance efforts at prevention [1]." According to United nation international children's emergency fund, 2016 child marriage is one of the main forms of child sexual abuse represents perhaps the most prevalent form of sexual abuse and exploitation of girls".

"The global prevalence of child sexual abuse has been estimated at $19.7 \%$ for females and $7.9 \%$ for males [2]." Most sexual abuse offenders are acquainted with their victims; approximately $30 \%$ are relatives of the child, most often brothers, fathers, uncles, or cousins; around $60 \%$ are other acquaintances, such as "friends" of the family, babysitters, or neighbors; strangers are the offenders in approximately $10 \%$ of child sexual abuse cases [3]." Most child sexual abuse is committed by men; studies on female 
child molesters show that women commit $14 \%$ to $40 \%$ of offenses reported against boys and $6 \%$ of offenses reported against girls [3]." Gender is also a major factor in sexual abuse. Females are five times more likely to be abused than males [4]."

"Age is a significant factor in sexual abuse. While there is risk for children of all ages, children are most vulnerable to abuse between the ages of 7 and 13 [5]. The median age for reported abuse is 9 years old [6]. However, more than $20 \%$ of children are sexually abused before the age of 8 [7]. "The age of the male being abused also plays a part. $8 \%$ of victims age $12-17$ are male and $26 \%$ of victims under the age of 12 are male [7]."

"Child sexual abuse can occur in a variety of settings, including home, school, or work in places where child labor is common. "Most sexual abuse of children occurs in a residence, typically that of the victim or perpetrator. $84 \%$ of sexual victimization of children under age 12 occurs in a residence. Even older children are most likely to be assaulted in a residence. $71 \%$ of sexual assaults on children age $12-17$ occur in a residence [7]."

"The risk of sexual abuse is tripled for children whose parents are not in the labor force [4]. Children in low socioeconomic status households are 3 times as likely to be identified as a victim of child abuse [4]." Most studies have reported that children with disabilities are at greater risk for sexual abuse. The latest research identified incidents of child sexual abuse involving children with disabilities at only half the rate of their non-disabled peers. Children who live in rural areas are almost two times more likely to be identified as victims of child sexual abuse [4]. Children who witness or are the victim of other crimes are significantly more likely to be sexually abused [5].

"Most child sexual abusers are men, and may be respected members of the community drawn to settings where they gain easy access to children like schools, clubs and churches. They come from all age groups, races, religions and socioeconomic classes [5]". Researchers attempted to evaluate the predictive accuracy of ten specific risk factors for child molesters [8]. "The risk factors examined were: amount of contact with children, degree of sexual preoccupation with children, impulsivity, juvenile and adult antisocial behavior, frequency of prior sexual offenses, paraphilia's, and history of alcohol use, social competence, and victim gender [8]."

"Perpetrators are mainly male adults and youth who are known to the child, in particular relatives and acquaintances [9]". Limited research has been conducted with perpetrators in South Africa. Such studies suggest that perpetrators are more likely to have a history of childhood sexual or physical abuse, as well as witnessing the violence towards their mothers [10]". Perpetrators report that they look for passive, quiet, troubled, lonely children from single parent or broken homes (11). Perpetrators frequently seek out children who are particularly trusting (12) and work proactively to establish a trusting relationship before abusing them [11]. "Not infrequently, this extends to establishing a trusting relationship with the victim's family as well [13]".

"Many perpetrators "groom" victims and their families. Many establish a trusting relationship with the victim's family [13], in order to gain access to the child [14]. Perpetrators employ successively inappropriate comments and increasingly inappropriate touches and behaviors so insidious that the abuse is often well under way before the child recognizes the situation as sexual or inappropriate [14]." Child sexual abuse often takes place under specific, often surprising circumstances. It is helpful to know these circumstances because it allows for the development of strategies to avoid child sexual abuse. $81 \%$ of child sexual abuse incidents for all ages occur in one-perpetrator/onechild's circumstances. 6-11 year old children are most likely and $23 \%$ to be abused in multi-victim circumstances [7]".

"The impact of child sexual abuse can be understood in terms of who the perpetrator is, the duration of the abuse and the age of the child at the onset and responses to disclosure [15]". For some children this trauma is internalized and they present with severe psychosomatic responses, like headaches, stomach aches, and loss of appetite before disclosure [16]". "Factors such as parent-child relationship and family functioning also play an important role in how a child adjusts post rape, as this directly affects the support the child receives post-disclosure [13]". "These factors have been shown to be particularly pronounced during the adolescent phase, with caregivers more likely to blame the child and thus influence recovery [17]".

"Child sexual abuse has a profound impact on the physical and mental health of its victims, with both immediate, as well as longer-term consequences and is of major concern [18]". Health outcomes may include HIV infection, sexually transmitted infection, unwanted pregnancy, unsafe abortion and a range of adverse reproductive health consequences [19]". "The effects of child sexual abuse can include depression, [20], posttraumatic stress disorder [21], anxiety [22] complex post traumatic stress disorder, [23] propensity to further victimization in adulthood, [24] and physical injury to the child, among other problems [25]". Sexual abuse by a family member is a form of incest and can result in more serious and long-term psychological trauma, especially in the case of parental incest [26]".

"Societal and cultural norms related to the social position of children, child rearing practices, as well as the breakdown of immediate and extended family systems, orphaned children and child-headed households all contribute to children's vulnerability to child sexual abuse [27]".

"In some instances, sexual abuse is used as a means to punish a mother or the girl child, with rape used as a display of control [28]". Children are socialized to respect and to be obedient to their elders, with harsh methods of discipline still used to enforce parental control [29]". This unquestionable authority of adults, allows for sexual violence to occur without much resistance from children [10]". "Teachers, in their position of authority, also hold significant power over school children; therefore, sexual abuse by teachers has been found to be a significant problem in South African schools 
[28]". These unequal power relations, thus, provides men with the space to sexually abuse children."

"There are child and family characteristics that significantly heighten or lower risk of sexual abuse [4]". The following risk factors are based on reported and identified cases of abuse. Family structure is the most important risk factor in child sexual abuse. Children who live with two married biological parents are at lower risk for abuse. The risk increases when children live with step-parents or a single parent. Children living without either parent are 10 times more likely to be sexually abused than children that live with both biological parents. Children who live with a single parent that has a live-in partner are at the highest risk: they are 20 times more likely to be victims of child sexual abuse than children living with both biological parents [4]."

\section{Research Question}

\subsection{The main Research Question}

What are the risk factors for child sexual abuses and perpetrator related risk factors in the unit for treatment of children who needs special attention clinic, at the Adama Hospital Medical College.

\subsection{Sub Research Questions}

(1). What are the risk factors for child sexual abuse?

(2). What are the perpetrators related risk factors in child sexual abuse?

(3). What are the demographic factors for child sexual abuse?

\section{Objective of the Study}

\subsection{The Major Objective of the Study}

The major objective of the study is to identify and assess risk factors for child sexual abuse and perpetrator related risk factors in one center unit for treatment of children who needs special attention clinic at Adama Hospital medical college.

\subsection{The Specific Objectives Are}

(1). To assess risk factors for child sexual abuse

(2). To identify perpetrators related risk factors in child sexual abuse

(3). To describe demographic factors in child sexual abuse

\section{Methodology}

\subsection{Research Design}

This paper is based on cross sectional study designs to address the objectives of the study: to assess and identify the risk factors for child sexual abuse and perpetrators related risk factors in the unit for children who needs special attention at Adama Hospital medical college. A survey study portrays the status of a phenomenon at a particular time, determines what happened during a given activity and deals with the relationships between variables. It mainly focuses on research design, test and measurement procedure of a reality and statistical analysis to respond to research questions requiring numerical data [30]. Through the application of a survey, generalizations can be developed [31]. The selection of the use of a survey is, therefore, to generalize the findings from the sample to the entire population in the selected area. In addition, a systematic review and descriptive analysis were employed to see the risk factors for child sexual abuse and perpetrator related risk factors in the case of sexually abused children at Adama Hospital Medical College one stop center unit for children who needs special attention clinic.

\subsection{Population}

All sexually abused children were coming to Adama Hospital medical college from Adama city and outreach rural area are the target of the study. From the total population, it has been estimated that $19.7 \%$ of females and $7.9 \%$ of male children are sexually abused worldwide [2] and about 480 sexually abused children seen at Adama Hospital Medical college as unit for children who needs special clinic 2016 report reveals in which 115 of them are an attempt.

\subsection{The Sample}

The source population to address the objectives was all sexually abused children, who is communicating and ethical, cooperative clients appear in the study area. The selection of these clients was made from age registered in the patient card in the unit for children who needs special attention clinic. Thus, the total number of clients that the researcher enrolled in this study was three hundred samples with the expectation that some of them are non-responsive. Thus, for risk factors of child sexual abuse and their perpetrators sexually abused clients who are found to be responsive or immediate relative were interviewed for six consecutive months. Sexually abused children who are incoherent, lacks complete information, who fails to decide, non -cooperative due to fear of the outcome are not included in the study.

\subsection{Instrumentation}

For the study of the risk factors for child sexual abuse and perpetrator related risk factors, a questionnaire was developed from literature review according to the objective of the study. The questionnaire was used because these types of question format provide the frame of reference for all respondents to use in determining their answers. A questionnaire was used as a means to measure whether any treatments for child sexual abuse were sought. The questionnaire asks respondents to indicate for each of the behavior that are manifested. The instrument is also designed to determine the risk factors for child sexual abuse and perpetrators related risk factors in child sexual abuse. It is further used to determine how parents perceive the physical and emotional problem of sexually abused children, and to manage chronic problem of the sexually abused children. The 
developed questionnaire has two parts and twenty three items. In the strength of the survey questionnaire, important measuring scale is applied yet manageable for clients to read and complete. The validity of the developed questionnaire was tested by five experts who have second degree and higher (psychologist, psychiatrist, $\mathrm{MPh}$, gynecologist and $\mathrm{PhD}$ in public health). The translation of the questionnaire from English to Amharic were done and then converted to the English language by expert professionals to check for language equivalence. A pilot study was conducted prior to the main data collection for $10 \%$ of sexually abused children and analyzed to check the reliability of the instruments. The assessment showed that the questionnaire was acceptable and feasible with high reliability of $\alpha 0.74$. In accordance with findings of pretest, minor modifications were made to the questionnaire. The translated questionnaire was tested for feasibility of use, and acceptability. In accordance with findings of pretest, minor modifications were made to the questionnaire. The question and statements were grouped and arranged according to proposed objective.

\subsection{Data Processing and Analysis}

With regard to data management, all completed questionnaire forms was reviewed by data collector and checked by a researcher. Forms with missing data returned to the interviewer immediately for correction. The data were categorized and coded on the well-defined coding sheet. Later it was exported to SPSS statistical software for windows version 20 for analysis. Descriptive statistics as frequency, percentage, means, and median range was generated. The analysis focuses on the pretest conceptual analysis and descriptive analyses were done based on the objective of the study.

\subsection{Ethical Consideration}

To conduct the study, the research proposal was examined and screened for scientific and ethical clearance by institutions, research highest body for approving research in the college of medical science, Adama Hospital Medical College. Prior to administering the survey and collecting data, permission letter was given to, Adama Hospital medical college and authorities of different levels including the department where the study was conducted. The researcher also asked permission from respondents' parent and sexually abused a client to gain full commitment about the study.

\section{Result and Discussion}

\subsection{Results}

Table 1. Demographic characteristics of sexually abused children and their perpetrators.

\begin{tabular}{|c|c|c|c|}
\hline Variable & & Frequency & Percent \\
\hline \multicolumn{4}{|c|}{ Sex of the child } \\
\hline 1 & Male & 6 & 2 \\
\hline 2 & Female & 294 & 98 \\
\hline \multicolumn{4}{|c|}{ Is perpetrator known by the child? } \\
\hline 1 & Yes & 269 & 89.7 \\
\hline 2 & NO & 31 & 10.3 \\
\hline \multicolumn{4}{|l|}{ Education } \\
\hline 2 & LKG/ UKG & 8 & 2.7 \\
\hline 3 & $1-8$ grade & 214 & 71.3 \\
\hline 4 & $8-12$ grade & 22 & 7.3 \\
\hline \multicolumn{4}{|c|}{ Previous history of sexual abuse } \\
\hline 1 & Yes & 20 & 6.7 \\
\hline 2 & No & 280 & 93.3 \\
\hline \multicolumn{4}{|c|}{ Family income } \\
\hline 3 & $>300 \mathrm{Birr} / \mathrm{month}$ & 13 & 4.3 \\
\hline \multicolumn{4}{|c|}{ Family size in the household } \\
\hline 1 & Loner & 4 & 1.3 \\
\hline 2 & 2-5 individuals in a household & 163 & 54.3 \\
\hline 3 & $>6$ individuals in the household & 133 & 44.4 \\
\hline \multicolumn{4}{|c|}{ Any physical/ mental disability before sexual abuse? } \\
\hline 1 & Yes & 24 & 8 \\
\hline 2 & NO & 276 & 92 \\
\hline \multicolumn{4}{|c|}{ Number of Perpetrators } \\
\hline 1 & Person alone & 269 & 89.7 \\
\hline 2 & Group assault & 31 & 10.3 \\
\hline \multicolumn{4}{|c|}{ Is perpetrator ------------------? } \\
\hline 1 & Alcoholic & 56 & 18.6 \\
\hline 2 & Multi drug abuser & 75 & 24.9 \\
\hline 3 & Had repeated history of child sexual abuse & 1 & 0.3 \\
\hline
\end{tabular}




\begin{tabular}{lll}
\hline Variable & & Frequency \\
\hline 4 & Recognized mental illness & 0 \\
5 & Not known & 168 \\
Social status of offender & & 56.2 \\
1 & Managers & 5 \\
2 & Daily laborer & 62 \\
3 & Religious leader & 1.7 \\
4 & Civil servant & 20.6 \\
5 & Student & 0.3 \\
6 & Others (drivers, farmer, jobless, etc.) & 4.7 \\
\hline
\end{tabular}

According to table 1 majority of risk factors for child sexual abuse and perpetrators related risk factors in the unit for children who needs special attention clinic is assessed, identified and stated clearly. From the total of 300 sexually abused children, 294 of them are female sex and only 6 of them are male. In $89.7 \%$ of the case victims do not know their perpetrators. 241 of sexually abused children are at grade level
1-8. $20 \%$ of sexually abused children had previous episode in their past life. $95.7 \%$ of sexually abused child's family monthly income is bellow $130 \$$ and lives in ways that is comfortable for offenders to sexually abuse children. 24 children out of 300 who sexually abused suffer from any physical or mental disability. Regarding perpetrators 131 of them use alcohol and multi drug abuser in their daily life.
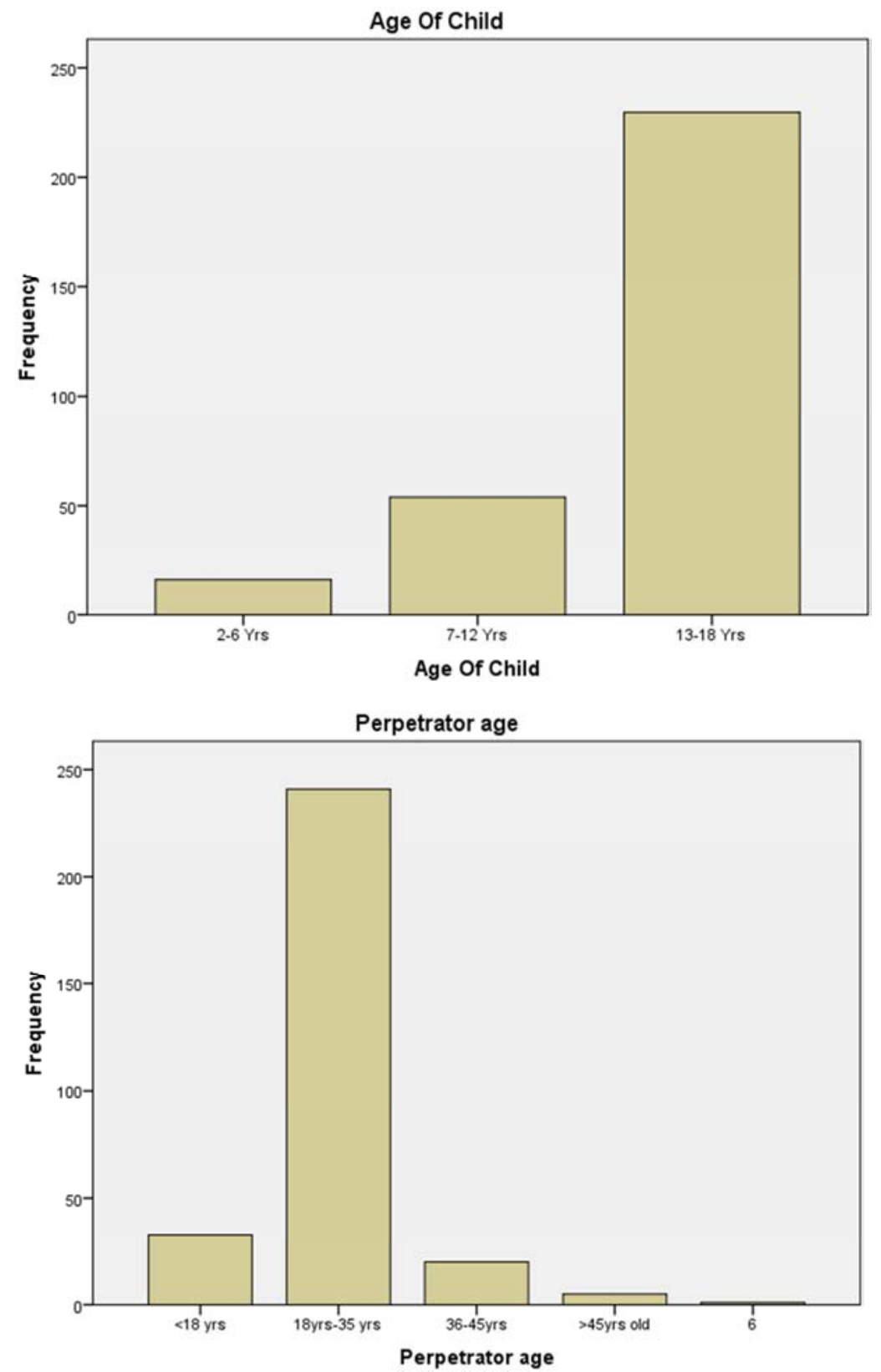

Figure 1. Showing age of sexually abused childeren and their perpetrators. 
Figure 1 try to show the close age relationship b/n sexually abused children and their perpetrators. Based on, 13-18yrs sexually abused children score higher (230) $76.7 \%$ and (241) $80.3 \%$ out of 300 perpetrators are in the age regimen of 18 yrs-35yrs.

\subsection{Discussion}

The findings from this study indicate that the risk factors for child sexual abuse and their perpetrators in one stop center unit for children who needs special attention clinic at the Adama Hospital Medical College are as the research literatures indicate. The resulting data closely mirrored national statistics for what is intended to measure, which suggests that the group that responded reasonably matches the national population as it is corresponded in the literature. Even though Child sexual abuse definitions have changed over the years as have the organizations that investigate child sexual abuse cases so statistics on child sexual abuse may inherently fluctuate, Natasha Tracy, [2015]. As was stated in the literature, the global prevalence of child sexual abuse has been estimated at $19.7 \%$ for females and $7.9 \%$ for males [2]". Child sexual abuse only accounts for about $8 \%$ of child abuse cases, Natasha Tracy, [2015]. In fact, only $30 \%$ of child sexual abuse cases are thought to be disclosed during childhood Natasha Tracy, [2015]. Previous 2015 document analysis study of the area by melal Bekele [MPH] reveals $94.1 \%$ and $5.9 \%$ female and male children respectively. In this study (294) $98 \%$ of sexually abused children's are female and only (6) $2 \%$ of them are males.

Age is a significant risk factor in sexual abuse. While there is risk for children of all ages, children are most vulnerable to abuse between the ages of 7 and 13 [5]. The median age for reported abuse is 9 years old [6]. However, more than $20 \%$ of children are sexually abused before the age of 8 [7]. In the study done at unit for children's who needs special attention clinic 2-6yrs score (16) $5.3 \%$ of the case, 7-12yrs score (54) $18 \%$ and $13-18 y$ yrs score (230) $76.7 \%$ out of 300 sexually abused children. The mean age of sexually abused children is 14 years and the minimum age is 2 years old during this study period in the area. According to Statistics done on Perpetrators of Child Sexual Abuse, Offenders are overwhelmingly male, ranging from adolescents to the elderly and some perpetrators are female. It is estimated that women are the abusers in about $14 \%$ of cases reported among boys and $6 \%$ of cases reported among girls [65]. In this study, even though all perpetrators are male, (292) $97.3 \%$ of being in $\mathrm{b} / \mathrm{n}$ male perpetrators and female child and (8) $2.7 \%$ of the perpetrators are $\mathrm{b} / \mathrm{n}$ male and male anal intercourse. Except (30) $9.9 \%$ of an attempt trial all in all as physical examination detects complete vaginal or anal tear is confirmed by gynecologist who are assigned in the clinic. Internationally one-third of offenders are themselves juveniles, $23 \%$ of reported cases of child sexual abuse are perpetrated by individuals under the age of $18 \mathrm{yrs}$ [65]. In this study juvenile perpetrators scores (33) 11\%, 18yrs-35yrs score (241) 80.3\%, 36-45yrs (20) 6.6\% and above $45 \mathrm{yrs}$ (6)
$2 \%$. The outcome study by the national center for crime, $14 \%$ of children who suffered sexual abuse were violated by unknown perpetrator whereas in this study (269) $87.7 \%$ and (31) 10.3 children's sexually abused by the perpetrators they do not know and they know each other's respectively with perpetrators at least once in their daily life.

Child sexual abuse often takes place under specific, often surprising circumstances. It is helpful to know these circumstances because it allows for the development of strategies to avoid child sexual abuse. $81 \%$ of child sexual abuse incidents for all ages occur in one-perpetrator/oneChilds' circumstances. 6-11 year old children are most likely $23 \%$ to be abused in multi-victim circumstances [7]. The result of this study, explore [269] 89.7\% sexually abuse committed by one perpetrator only and [31] 10.3 of them are sexually abused in group cohesion on more than one perpetrator. Concerning educational background of those victims [56] $18.7 \%$ sexually abused children never go to school, [8] 2.7\% in lower and upper grade level, [214] 71.3\% 1 - 8 grade and [22] $7.3 \%$ of them are at 9-12 grade.

Child sexual abuse is tripled for children whose parents are not in the labor force [4]. With regard to this study, parents of sexually abused children (227) $75.7 \%$ of them are married, (47) $15.7 \%$ are widowed, (16) $5.3 \%$ divorced/separated, (5) 1.7\% single parenthood and (5) 1.7 of them are self- child headed family. The current living condition while they are sexually abused (246) $82.0 \%$ lives with their parents, (10) $3.3 \%$ with their friends, (33) $11 \%$ fostered (9) $3.0 \%$ and (2) $0.7 \%$ at an orphanage. Constraints family life is one of the reasons in sexual abuse. According to this study (133) $44.3 \%$ sexually abused children, family size, in the household is (133) $44.4 \%>6$ individuals in a single house, (163) $54.4 \% 2-5$ individuals in a constrained family and only (4) $1.3 \%$ of them live in a single isolated room family size which create a good opportunity for children to be perpetrated. Children in low socioeconomic status households are three times as likely to be identified as a victim of child abuse [4]. In this study from the total of 300 sexually abused children (106) 35.3\% family income /month is $<45 \$$ (1000 Eth. Birr), (181) $60.3 \%$ per monthly income family generation is $\mathrm{b} / \mathrm{n}$ 46-136\$(1001-3000 Ethi Birr) and only (13) $4.3 \%$ of sexually abused children's parent earn $>136 \$(>3000)$ Ethio Birr /month. This implies that child sexual abuse in the study area is associated with low socioeconomic family background in which children's are participating in risky labor force.

Most studies have reported that children with disabilities are at greater risk for sexual abuse. The latest research identified incidents of child sexual abuse involving children with disabilities at only half the rate of their non-disabled peer [4]. However, in this study (24) $8 \%$ of sexually abused children have at least one or more recognized physical and mental disability and (276) $92 \%$ of them respond to none to sever physical or mental disorders.

Children who live in rural areas are almost two times more likely to be identified as victims of child sexual abuse [4]. 
Almost in this study, they are near to equal in which (141) $47 \%$ of them are from urban area and (157) $53 \%$ of children resident in the rural area, because lifestyle in rural and town is similar in developing countries even sometimes vice versa. Children who witness or are the victim of other crimes are significantly more likely to be sexually abused [5]. By this study (20) $6.7 \%$ of sexually abused children had experienced later life episode and (280) 93.3\% had never experienced in their life.

Sexual abuse of children occurs in a residence, typically that of the victim or perpetrator residence. $84 \%$ of sexual victimization of children under age 12 occurs in a residence. Even older children are most likely to be assaulted in a residence. $71 \%$ of sexual assaults on children age $12-17$ occur in a residence [7]. The study analysis (139) $46.3 \%$ of sexual abuse committed at perpetrators own residence, (74) $24.7 \%$ are at victim own home, (15) $5 \%$ at the garden while on daily activities, (12) $4 \%$ at the school environment while academic learning and (60) $20 \%$ at bush while on their journey for functional purposes. For all 300 sexually abused children an event happens (185) $61.7 \%$ during the day time and (115) $38.3 \%$ performed by using night time as their shadow.

Studies indicate that children are sexually abused by perpetrators of all ages. Accordingly, children are not only abused by adults but by fellow children. Sariola and Uutela (1994) have found out that there exists an age gap of five to sixteen years between the abuse and the abuser parties. In this study, the range of the abuser party was found to extend from 9 to 60 years old, with a mean age of 30 years during this study period. However, this clinical area study result indicates that young people between 18 and 35 commit (242) $80.7 \%$ of the offenses and the age range $<18$ yrs accounts for (33) $11 \%$ of the total offenses. Thus, it could be said that the perpetrators are usually young people.

Sexual abuse by stranger is not usually common and rather it starts in the near home surrounding settings. According to Melal Bekele 2015 conducted a similar study the most common perpetrators include neighbor $38.95 \%$, teachers $7.9 \%$, relatives at $13.4 \%$ and the remaining are other professionals. The study done by this research identifies the most common perpetrators are neighbor (146) $48.5 \%$, family members (25) $8.3 \%$, friends (13) $4.3 \%$, teachers (2) and the remaining percent do not mentioned by sexually abused children or their families. The study also tries to assess family members who committed sexual abuse on children. From the total of 25 sexually abused victims $47.6 \%$ is by cousin, $14.3 \%$ father, $4.8 \%$ by brothers, $14.3 \%$ uncle and the remaining percentage accomplished by other family members who have a close attachment with children's.

An international review and meta-analysis of risk factors for the perpetration of Child sexual abuse found that a history of sexual abuse, harsh discipline as a child, and difficulty with intimate relationships, antisocial behavior and loneliness were found to be positively associated [61]. Caregiver, alcohol or drug abuse is a child abuse risk factor putting kids at much higher risk of being abused, [58]. Alcohol and multi drug abuser commit child sexual abuse due to despaired mental activity and some of them present substance use as a defense mechanism for their guilty feelings. In the study done on perpetrators (56) $18.6 \%$ of them consume alcohol and (75) $25 \%$ of them are multi drug abuser in a daily life in which $1(0.3 \%)$ had identified repeated child sexual abuse in his past life. Concomitantly collected data also identify the social status of child sexual abuse perpetrators. Based on the study finding (5) $1.7 \%$ of sexual offenders are office managers, (1) $0.3 \%$ religious leader, (14) $4.7 \%$ are civil servants, (44) $14.6 \%$ are students, and the other remaining (173) $57.7 \%$ incorporate drivers, farmers and jobless individuals.

Finally the study generalizes its discussion on female sex, minimal age, constricted family life, low monthly income of the parents, low level of education attained by children's, parents unhappy marriage, participation of children in risk labor force, mental or physical disability of children are among the possible risk factors for child sexual abuse in one stop center unit for children who needs special attention clinic at the Adama Hospital Medical College. Similarly the perpetrators amount of contact with children, degree of sexual preoccupation with children, antisocial behavior, frequency of prior sexual offenses, psychiatric problems, and social status of perpetrators and history of alcohol and substance use disorders are perpetrators related factors in child sexual abuse that affects the life of children in any important part of their life.

\section{Conclusion}

As can be seen from the study findings, risk factors for child sexual abuse and perpetrators related risk factors in child sexual abuse are identified. Risk factors for child sexual abuse are female sex, minimal age, constricted family life, low monthly income of the parents, low level of education attained by children's, parents unhappy marriage and participation of children in risk labor force, physical and mental health of children collectively. The perpetrators amount of contact with children, degree of sexual preoccupation with children, juvenile and adult antisocial behavior, frequency of prior sexual offenses, psychiatric problems, and social status of perpetrators and history of alcohol and substance use disorders are perpetrators related factors in child sexual abuse that affects the life of children in any important part of their life.

\section{Acknowledgment}

The researcher would like to express his gratitude to all parties that have participated in the process of the study, and above all, to Ato Mekonnen Belete, Adama Hospital Medical College one stop center unit for children who needs special attention clinic director.

\section{Conflict of Interest and Funding}

The authors have not received any funding or benefits 
from governmental or non governmental, or elsewhere to conduct this study. Interest emanate from the wish to show participation in creating advanced turning point toward child sexual abuse to see disable free next generation from the trauma.

\section{References}

[1] Esther D, [2009]. The national child traumatic stress network, www, NCTSN org. London.

[2] Pereda N, Guilera G, Forns M, \& J Gomez-Benito, J [2009]. The prevalence of child sexual abuse in community and student samples: A meta-analysis", Clinical Psychology Review 29 (4): 328-338. doi: 10.1016/j.cpr.2009.02.007.

[3] Julia W, [2007]. Child Sexual Abuse", National Center for Posttraumatic Stress Disorder USA.

[4] Sedlak, A. J., Mettenburg, J., Basena, M., Petta, I., McPherson, K., Greene, A., and Li, S. [2010]. Fourth National Incidence Study of child abuse and neglect, Washington, DC: U.S.

[5] Finkelhor, D [1994]. Current information on the scope and nature of child sexual abuse, The Future of Children 4 (2): 31 53. Doi: $10.2307 / 1602522$.

[6] Putnam, [2003]. Treating psychological symptoms in sexually abused children, Uk.

[7] Snyder M, Stukas AA Jr [2000]. Interpersonal processes: The interplay of cognitive, motivational, and behavioral activities in social interaction. Ann Rev Psychol. 1999; 50: 273-303. [PubMed: 10074680].

[8] Proulx, J., Tardif, M., Lamoureux, B., Lussier, P. [2000]. How does recidivism risk assessment predict survival?

[9] Makoae, M., Warria, A., Bower, C., Ward, C., Loffel, J., \& Dawes, A. [2009]. South Africa country report on the situation on prevention of child maltreatment study, Cape Town.

[10] Townsend, L, \& Dawes, A. [2004]. Individual and contextual factors associated with the sexual abuse of children under 12: A review of recent literature. In L. Cape Town.

[11] Budin and Johnson, [1989]. National criminal reference system, USA.

[12] Conte et al. [1987]. Evaluating children's response of sexual abuse.

[13] Briere, J., \& Elliott, D. M. [1993]. Sexual abuse, family environment, and psychological symptoms: On the validity of statistical control. Journal of Consulting and Clinical Psychology, 61 (2), 284-288.

[14] Berliner and Conte, [1990]. Factors influencing children to self -disclose sexual abuse, University of Nebraska, Lincoln.

[15] Killian, B., \& Brakarsh, J. [2004]. Therapeutic approaches to sexually abused children. In L. Richter, A. Dawes \& C. Higson-Smith (Eds.), Sexual abuse of young children in southern Africa (pp. 367-394). Cape Town.
[16] Maniglio, R. [2009]. Severe mental illness and criminal victimization: A systematic review. Acta Psychiatrica Scandinavia, 119 (3), 180-191.

[17] Bergen, H. A., Martin, G., Richardson, A. S., Allison, S., \& Roeger, L. [2004]. Sexual abuse, antisocial behavior and substance use: Gender differences in young community adolescents. Australian and New Zealand Journal of Psychiatry, 38 (1-2), 34-41.

[18] World Health Organization, [2002]. World report on violence and health, Geneva: WHO.

[19] Clark, S., Bruce, J., \& Dude, A. [2006]. Protecting young women from HIV/AIDS: The case against child and adolescent marriage, International Family Planning Perspectives, 32 (2), 79.

[20] Roosa MW, Reinholtz C, Angelini PJ [1999]. "The relation of child sexual abuse and depression in young women: comparisons across four ethnic groups". Journal of Abnormal Child Psychology 27 (1): 65-76.

[21] Widom CS [August 1999]. "Posttraumatic stress disorder in abused and neglected children grown up", The American Journal of Psychiatry 156 (8): 1223-1229.

[22] Levitan RD, Rector NA, Sheldon T, Goering P [2003]. "Childhood adversities associated with major depression and/or anxiety disorders in a community sample of Ontario: issues of co-morbidity and specificity, Depression and Anxiety.

[23] Roth, Susan; Newman, Elana; Pelcovitz, David; Van Der Kolk, Bessel; Mandel, Francine S. [1997]. "Complex PTSD in victims exposed to sexual and physical abuse: Results from the DSM-IV field trial for posttraumatic stress disorder, Journal of Traumatic Stress.

[24] Messman, Moore, T, L.; Long, P. J. [2000]. "Child Sexual Abuse and Re victimization in the Form of Adult Sexual Abuse, Adult Physical Abuse, and Adult Psychological Maltreatment", Journal of Interpersonal Violence 15 (5): 489.

[25] Dinwiddie S, Heath AC, Dunne MP, et al. [2000]. "Early sexual abuse and lifetime psychopathology: a co-twin-control study". Psychological Medicine.

[26] Courtois, Christine A. [1988]. Healing the incest wound: adult survivors in therapy. USA.

[27] World Health Organization. [2010]. Report on violence and health in Africa. Brazzaville: World Health Organization, "Regional Office for Africa.

[28] Abrahams, N., Jewkes, R., Laubscher, R., \& Hoffman, M. [2006]. Intimate partner violence: Prevalence and risk factors for men in Cape Town, South Africa. Violence and Victims, 21 (2), 247-264.

[29] Guma, M, \& Henda, N, [2004]. The socio-cultural context of child abuse: A betrayal of trust. In L. Richter, A. Dawes.

[30] Williams, C [2007]. Research method, Journal of economic research, 5, 65-72.

[31] Best and Kahn [2006]. Leedy \& Ormord, [2001]. Conducting survey research in education, University of Tennessee, USA. 